\title{
Protein quality control of cell stemness
}

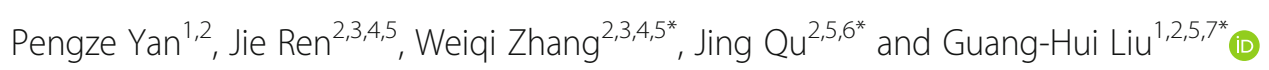

\begin{abstract}
Protein quality control (PQC) systems play essential roles in the recognition, refolding and clearance of aberrant proteins, thus ensuring cellular protein homeostasis, or proteostasis. Especially, continued proliferation and differentiation of stem cells require a high rate of translation; therefore, accurate PQC systems are essential to maintain stem cell function. Growing evidence suggested crucial roles of PQC systems in regulating the stemness and differentiation of stem cells. This review focuses on current knowledge regarding the components of the proteostasis network in stem cells, and the importance of proteostasis in maintaining stem cell identity and regenerative functions. A complete understanding of this process might uncover potential applications in aging intervention and aging-related diseases.
\end{abstract}

Keywords: Protein quality control, Stem cells, Stemness, Chaperones, Unfolded protein response, Ubiquitinproteasome system, Autophagy

\section{Background}

Stem cells serve as the origin of a multicellular organism. They can divide to give rise to daughter cells that remain as stem cells or become differentiated with a specific function. The multi-differentiation potential gives stem cells unparalleled advantages in regenerative medicine. Originally, stem cells can be categorized into two main groups: embryonic stem cells (ESCs) and adult stem cells (ASCs). Yet with the development of reprogramming technologies, somatic cells can also be reprogrammed into ESC-like cells, termed as induced pluripotent stem cells (iPSCs). Collectively, ESCs and iPSCs are referred to as pluripotent stem cells (PSCs) because of their high capacity for selfrenewal and their ability for multipotent differentiation, offering far-reaching potential in disease modeling and transplant therapies (Evans and Kaufman, 1981; Shu et al., 2013; Yamanaka, 2009). On the other hand, ASCs are undifferentiated cells distributed throughout the body, and have the ability to differentiate into several restricted cell types and to participate in tissue regeneration (Passier and

\footnotetext{
* Correspondence: zhangwq@big.ac.cn; qujing@ioz.ac.cn; ghliu@ioz.ac.cn

${ }^{2}$ University of Chinese Academy of Sciences, Beijing 100049, China

${ }^{1}$ State Key Laboratory of Membrane Biology, Institute of Zoology, Chinese

Academy of Sciences, Beijing 100101, China

Full list of author information is available at the end of the article
}

Mummery, 2003; Wagers and Weissman, 2004). Due to their lower immunogenicity and higher safety profile, certain ASCs (eg. MSCs) are recognized as the most promising source for cell therapy (Kode et al., 2009; Pessina and Gribaldo, 2006).

Researches focused on stem cells have attracted much attention in recent years, with a particular focus on the transcription factor networks that regulate their stemness and differentiation (Avilion et al., 2003; Chambers et al., 2003; Cui et al., 2018; Nichols et al., 1998; Wang et al., $2019 \mathrm{~b})$. Other aspects of regulation, such as miRNAs and epigenetic modifications, have also been studied extensively (Atlasi and Stunnenberg, 2017; Avgustinova and Benitah, 2016; Croce and Calin, 2005; Foshay and Gallicano, 2009; Hsieh and Gage, 2004; Martinez and Gregory, 2010; Meissner, 2010; Shenoy and Blelloch, 2014; Wang et al., 2007; Wu and Sun, 2006; Yu et al., 2012). Although there has been less focus on posttranslational mechanisms of regulation, recent studies indicate that there is a close connection between protein quality control (PQC) and stem cell function (Assou et al., 2009; Bradley et al., 2012; Buckley et al., 2012; Fernandes et al., 2019; García-Prat et al., 2017; Geng et al., 2015; Heijmans et al., 2013; Hernebring et al., 2013; Jang et al., 2014; Kapetanou et al., 
2017; Noormohammadi et al., 2018; Saretzki et al., 2004; Schroter and Adjaye, 2014; Vilchez et al., 2013).

A single cell contains billions of proteins with a total concentration ranging from 50 to $300 \mathrm{mg} / \mathrm{ml}$ (Asherie, 2004; Finka and Goloubinoff, 2013). Genetic mutation, transcriptional or translational errors, protein misfolding and aggregation can all lead to the generation of aberrant proteins (Goldberg, 2003; San Jose et al., 2020; Sigurdsson and Miharada, 2018). These aberrant proteins may form toxic aggregates and cause deleterious effects on cell function and viability, which may ultimately lead to human diseases (Balch et al., 2008; Bennett et al., 2005; Gidalevitz et al., 2011; Koyuncu et al., 2018; Powers et al., 2009; San Jose et al., 2020). In addition, accumulation of aberrant proteins in stem cells may also contribute to the aging process (Kapetanou et al., 2017; Vilchez et al., 2014b; Wang et al., 2018b).

To prevent aberrant proteins from accumulating, cells have evolved an elaborate network of PQC systems to recognize abnormal proteins and to facilitate their refolding or degradation (Fig. 1) (Chen et al., 2011; Goldberg, 2003; Leeman et al., 2018; Revuelta and Matheu, 2017; Richter et al., 2010). PQC systems operate since the beginning of polypeptide synthesis to avoid creating aberrant proteins, by altering the rate of translation that is dependent on the organization of ribosomes (Gingold and Pilpel, 2011; Wolff et al., 2014). There are also several pathways that ensure proteostasis after protein synthesis. Under stress conditions, the accumulation of misfolded and unfolded proteins in the cytoplasm, endoplasmic reticulum (ER), and mitochondria triggers the unfolded protein response (UPR). If aberrant proteins cannot be rescued by chaperones and the UPR pathway, they will be degraded via the ubiquitin-proteasome system (UPS) or autophagy pathways for the cell to regain protein homeostasis (Vilchez et al., 2014b). A study of the proteomic features of human embryonic stem cells (hESCs) during selfrenewal stage, classified about 60 proteins as the most abundant proteins. Most of these are chaperones and UPS components (Baharvand et al., 2006), indicating that PQC systems are of great importance in maintaining stem cell pluripotency.

In this review, we highlight the importance of proteostasis in stem cells with recent advances that revealed central mechanisms by which the proteostasis network regulates stem cell function. A thorough understanding of these mechanisms will be crucial for harnessing the therapeutic potentials of stem cells and for maximizing their utility as models to understand development and diseases.

\section{Pathways controlling protein folding in stem cells}

Proteostasis has been recognized as the cornerstone of stem cell homeostasis. The regulation of protein folding and recognition of abnormal products involve multiple components, which mainly belong to the chaperone family and the UPR pathway (García-Prat et al., 2017). In the following subsections, we discuss the critical roles of molecular chaperones and UPR in regulating cell stemness.

\section{Chaperones}

Chaperones, which themselves are under precise regulation in the cell, are initially considered as protein folding assistants (Fink, 1999). Later, some chaperones are also found to involve in signaling the ER stress response, delivering misfolded proteins for degradation, and breaking up protein aggregates (Jarosz et al., 2010; Mcclellan et al., 2005; Taipale et al., 2010; Trepel et al., 2010). There are several different groups of chaperones, whose nomenclature is typically based on their molecular weight and stimuli in the original studies. The first group consists of highmolecular weight heat shock proteins (HSPs), including the HSP110, HSP90, HSP70, and HSP60 families. The

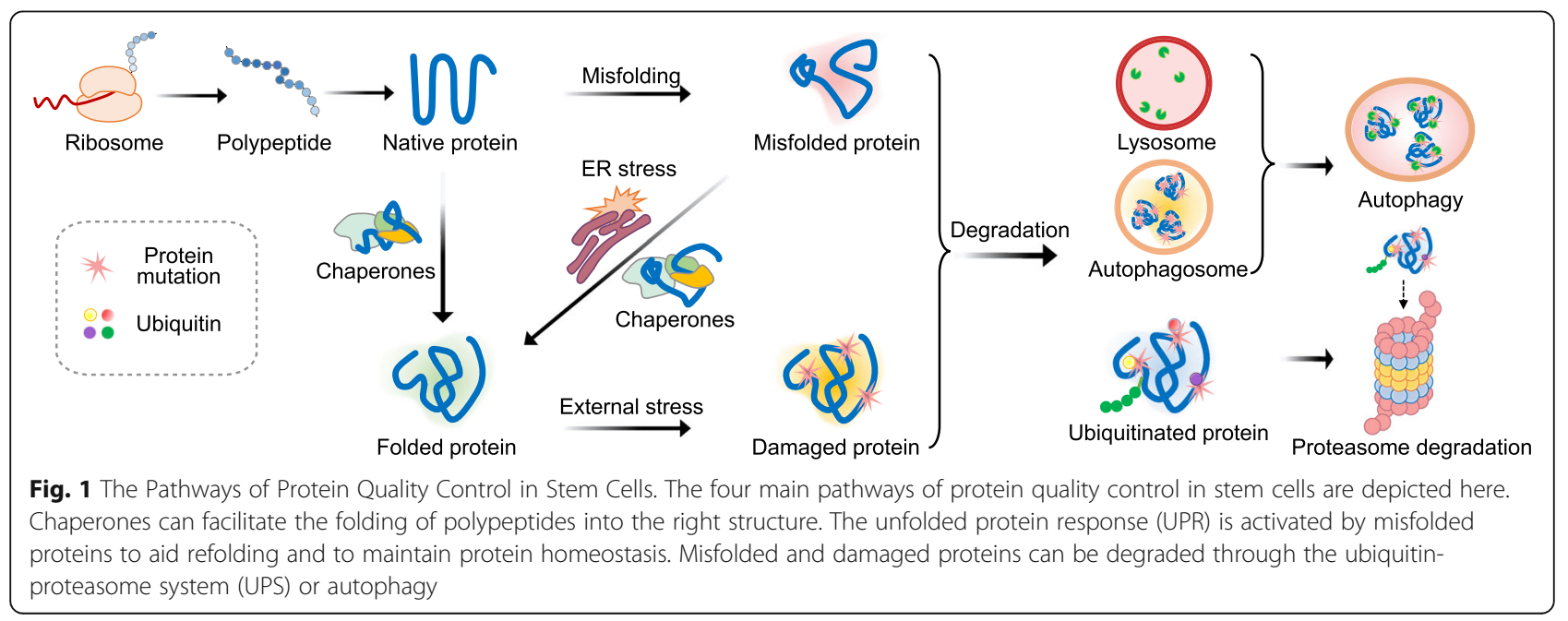


second group of HSPs, induced by glucose starvation, includes glucose-regulated proteins (GRPs) 75 (HSPA9), 78 (HSPA5), and 94 (HSP90B1). The third group of HSPs, mainly located in the extracellular matrix, includes HSP40, HSP47, and HSP56 (Boudesco et al., 2018; Jee, 2016; Michels et al., 1997; Sterrenberg et al., 2011). Small HSPs including HSPB1-B10, whose molecular weights range from 12 to $30 \mathrm{kDa}$, are categorized as the fourth group (Fan and Kranias, 2011; Kappe et al., 2003; Sciandra and Subjeck, 1983). By analyzing proteomic profiles of human cells, numerous chaperones and co-chaperones have been identified as potential regulators that help to delay aging and aging-related diseases (Baharvand et al., 2006; Brehme et al., 2014).

Levels of HSPs are higher in stem cells than in differentiated cells. For instance, HSPs such as HSPA1a, HSPA1b, HSPA9, and HSPB1 are highly expressed in both human and mouse embryonic stem cells (mESCs), while such high levels of expression diminish during differentiation (Baharvand et al., 2006; Battersby et al., 2007; Saretzki et al., 2004; Saretzki et al., 2008). Joint analysis of expression profiles of chaperones in human ESCs, mesenchymal stem cells (MSCs), and neural stem cells (NSCs) showed that high levels of HSPA5, HSPA8, and Stip1 expression are shared by these different types of stem cells (Baharvand et al., 2007). hESCs show a unique chaperone expression signature of HSPA4, HSPB1, and HSPCb (Baharvand et al., 2007). On the other hand, changes in the expression of certain HSPs may serve as differentiation markers of ESCs (Fan, 2012). For example, expression of HSP60, HSP70, HSP25 and co-chaperone Hop were greatly reduced during mESC differentiation (Baharvand et al., 2008; Baharvand et al., 2007; Battersby et al., 2007). Similarly, expression of HSPB1, HSPB5, and HSP60 decreases during differentiation of human adipose-derived ASCs (Delany et al., 2005). Yet, certain HSPs, such as HSPB1, do not decrease during hESC differentiation, but decrease during mESC differentiation (Saretzki et al., 2008), indicating differences in the proteostasis network between hESCs and mESCs. Nonetheless, high levels of chaperones may capacitate stem cells with greater abilities to cope with aberrant proteins and to maintain cellular homeostasis than differentiated cells. The main differences in the levels of chaperones between stem cells and differentiated cells are summarized here in Fig. 2.

In addition to the aforementioned correlative links, causal relationships have also been established between chaperones and stemness. For example, suppressing HSP90 expression contributed to mESC differentiation, at least partially because HSP90 protects Oct4 and Nanog from degradation by the proteasome (Bradley et al., 2012). Hsp90 $\beta$ knockout mice are embryonically lethal (Voss et al., 2000). The expression of HSP70 and HSP90 promotes survival of bone marrow MSCs after heat shock treatment (Wang et al., 2019a). HSP90 plays an important role in controlling the formation of hepatic progenitor cells by directly interacting with HNF4A protein, an essential transcription factor for hepatic progenitor specification from hPSCs (Jing et al., 2017). In addition, the absence of HSP60 is associated with the silencing of Oct4, and its deficiency can inhibit the proliferation and self-renewal of $\mathrm{mESCs}$, and promote apoptosis as well (Seo et al., 2018).

Besides individual chaperone proteins, hPSCs also exhibit enhanced assembly of the TRiC/CCT complex, a chaperonin that promotes the folding of roughly $10 \%$ of the whole proteome and reduces toxic protein aggregation (Noormohammadi et al., 2016). CCT8, one subunit of the TRiC/CCT complex, has been identified as a key promoter of its assembly and ectopic expression of CCT8 is also sufficient to increase its assembly (Noormohammadi et al., 2016). On the contrary, during the differentiation of neural stem and progenitor cells (NSPCs), the level of $\mathrm{TRiC} / \mathrm{CCT}$ complex is reduced, while small heat shock proteins are induced, thus promoting the sequestration of misfolded protein into protective inclusions and maintaining proteostasis (Vonk et al., 2020). A thorough investigation of chaperone networks in stem cell maintenance and differentiation is needed to aid our understanding of its vital role in enhancing cellular function.

\section{Unfolded protein response}

The endoplasmic reticulum (ER) is a central cellular organelle in proteostasis. It is involved in the synthesis, modification, and delivery of proteins to their target sites in the secretory pathway and the extracellular space (Schroder and Kaufman, 2005). Under ER stress conditions, the ER unfolded protein response $\left(\mathrm{UPR}^{\mathrm{ER}}\right)$ is activated to cope with misfolded proteins, either facilitating their proper re-folding or delivering them for degradation via the proteasome or autophagy pathways (Araki and Nagata, 2011). Growing evidence has revealed the significance of UPR in the pathogenesis of diseases, such as cancer, metabolic syndromes and aging-related diseases (Hetz et al., 2020; Huang et al., 2019; Martínez et al., 2018; Urra et al., 2016; Wang et al., 2018a).

In the ER homeostasis, GRP78 (also named as BiP) is a central regulator, as it plays a vital role in protein folding, ER calcium binding, and regulating the activities of transmembrane ER stress sensors. Consistently, Grp78 homozygous knockout mouse embryos failed to hatch from zona pellucida, and exhibited proliferation defects and extremely high levels of apoptosis in the inner cell mass, demonstrating that Grp78 is crucial for embryonic cell growth and pluripotent cell survival (Luo et al., 2006). The signals of protein folding status are transduced to the cytosol and nucleus through activation of three different ER transmembrane proteins: ATF6 (activated 


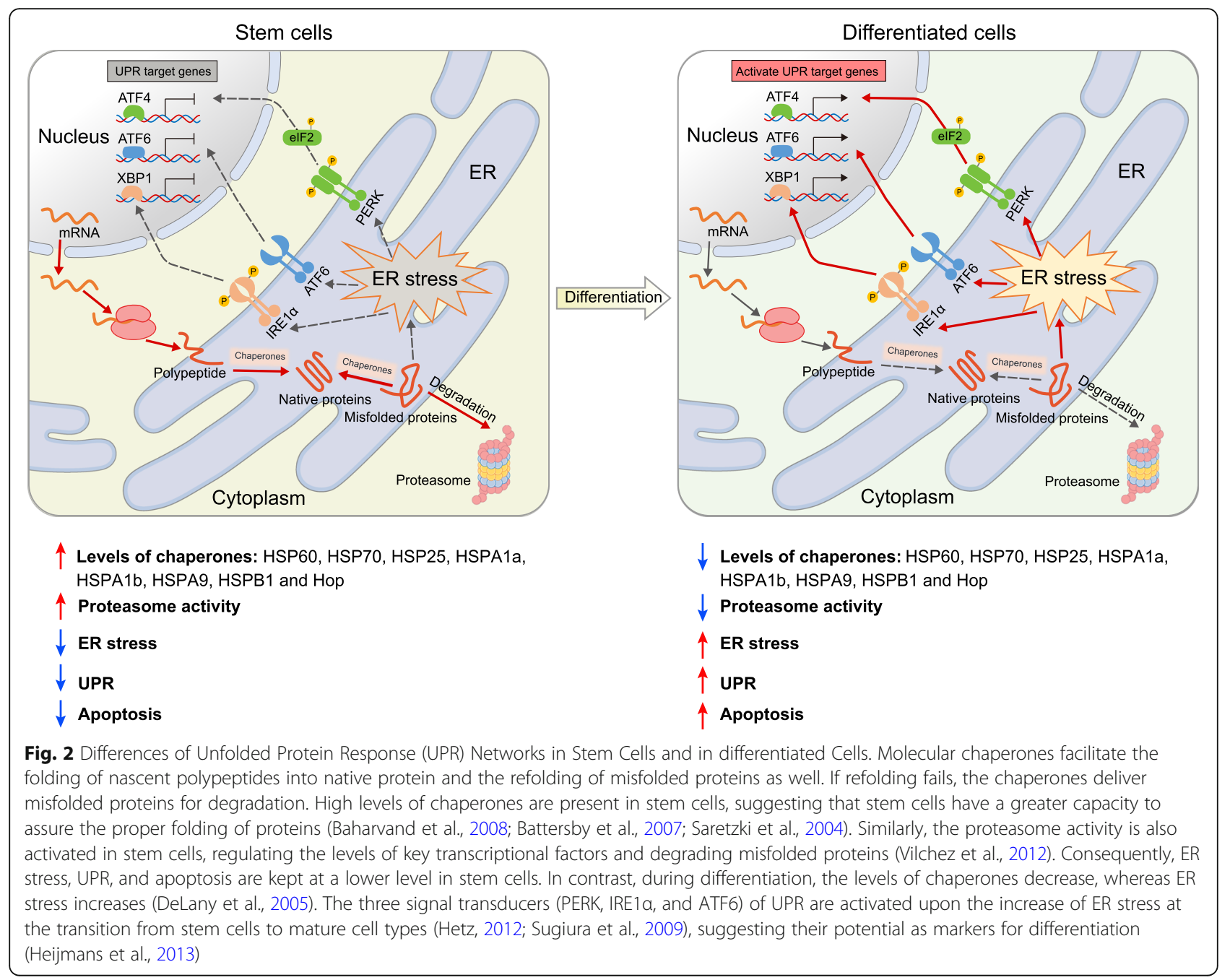

transcription factor 6), PERK (double stranded RNA activated protein kinase-like ER kinase), and IRE1 $\alpha$ (inositolrequiring transmembrane kinase and endonuclease) (Hetz, 2012). Clear proof for the impact of the UPR in ESC differentiation comes with activation of ATF6 by Dickkopf homolog 3, which promotes the differentiation of ESCs into smooth muscle cells (Wang et al., 2015).

Besides ESCs, the UPR pathway also regulates the selfrenewal and differentiation of ASCs. For example, overexpressing the co-chaperone ERDJ4 (also named as DNAJB9) enhances ER protein folding, thereby increasing the repopulation capacity of hematopoietic stem cells (HSCs) in xenograft assays, connecting the UPR to the maintenance of HSC properties (van Galen et al., 2014). In human iPSC-derived cardiomyocytes, PAK2 (p21-activated kinase 2) activation can enhance ER function, reduce cell apoptosis, and protect from heart failure through the IRE1 $\alpha /$ XBP1 (X-box binding protein 1)-dependent pathway (Binder et al., 2019). On the contrary, hematopoietic stem and progenitor cells (HSPCs) with HIF-2 $\alpha$ knockout exhibit high levels of reactive oxygen species (ROS), which subsequently induces ER stress and apoptosis via activation of the UPR pathway (Rouault-Pierre et al., 2013). Similarly, inactivation of ATF6 impairs the ER tubular network of human MSCs and eventually leads to cellular senescence (Wang et al., 2018b). Likewise, human HSCs show a proapoptotic phenotype to prevent the proliferation of damaged stem cells after activation of the PERK branch of the UPR pathway during ER stress, as damaged HSCs are rapidly cleared whereas closely related progenitors are spared (van Galen et al., 2014). The PERK branch of the UPR has also been found to regulate the homeostasis of skeletal muscle stem cells (also known as satellite cells) during regenerative myogenesis and is crucial for their survival after activation from quiescence (Xiong et al., 2017). On the other hand, during the differentiation of rat bone marrow stromal cells and mESCs into neurons, three branches of the UPR are activated, accompanied by the expression of neuronal markers (Cho et al., 2009). ER stress during the transition from stem cells to differentiated cells activates 
UPR, and multipotency is lost in a PERK-eIF2-dependent manner after ER stress (Heijmans et al., 2013).

In addition to UPR ${ }^{\mathrm{ER}}$, the mitochondrial unfolded protein response $\left(\mathrm{UPR}^{\mathrm{MT}}\right)$ also plays an important role in the maintenance of stem cell characteristics and homeostasis (Mohrin et al., 2018; Shen et al., 2020). SIRT7 inactivation can increase mitochondrial protein folding stress, reduce the regeneration ability of HSCs, and ultimately lead to aging (Mohrin et al., 2015). During stem cell reprogramming, $\mathrm{UPR}^{\mathrm{ER}}$ and $\mathrm{UPR}^{\mathrm{MT}}$ are both activated to ensure proteostasis, and the transient activation of $U P R^{E R}$ is an important step in the process of reprogramming (Simic et al., 2019).

\section{Pathways of aberrant protein degradation in stem cells}

With the decline of chaperone activity, aberrant proteins accumulate and are detrimental to stem cell function and homeostasis. Therefore, aberrant proteins are constantly removed by the UPS or through autophagy (Tanaka and Matsuda, 2014). Below we discuss recent evidence of the importance of the UPS and autophagy pathways in stem cells.

\section{Ubiquitin-proteasome system (UPS)}

In the UPS, damaged proteins are first tagged with multiple ubiquitin molecules and then recognized and proteolyzed by the proteasome (Glickman and Ciechanover, 2002; Mukhopadhyay and Riezman, 2007; Seifert and Kruger, 2008). Active proteasomes are mainly constituted by the $20 \mathrm{~S}$ core particle, which is the catalytic center, and the $19 \mathrm{~S}$ regulatory particle, which identifies the polyubiquitylated substrate and unfolds it for translocation into the 20S proteolytic core (Finley, 2009; Vilchez et al., 2014a). Thus, damaged proteins are digested to short peptides (Vilchez et al., 2014b).

The UPS is involved in the maintenance of pluripotency in ESCs by both promoting the degradation of differentiation-associated proteins and maintaining the homeostasis of pluripotency-associated proteins (Fig. 1) (Assou et al., 2009; Buckley et al., 2012; Cho et al., 2014; Hernebring et al., 2013; Jang et al., 2014; Vilchez et al., 2013; Vilchez et al., 2012). In general, proteasome activity is considerably higher in pluripotent cells than in differentiated cells (Vilchez et al., 2012). For example, both hESCs and iPSCs exhibit high proteasome activity, which is correlated with increased levels of the 19S proteasome subunit PSMD11 (Vilchez et al., 2012). And differentiation of hESCs to neural progenitor cells and to mature neurons is accompanied by downregulation of PSMD11 (Vilchez et al., 2012). Consequently, ubiquitin ligases, such as LIN41, UBR5 and USP21, are also regarded as important regulators in maintaining pluripotency and reprogramming of PSCs (Koyuncu et al., 2018; Liu et al., 2016b; Nguyen et al., 2017). When stem cells are treated with MG132, a proteasome inhibitor, the levels of pluripotency markers decrease and the levels of specific germ-layer markers (FGF5 and GATA4) increase (Assou et al., 2009; Vilchez et al., 2012). Transcription factors can also function through proteasome to control stem cell fate decision. For example, nuclear factor erythroid 2-like 2 (Nrf2) activates the expression of proteasome maturation protein (POMP), which in turn participates in hESC pluripotency and somatic cell reprogramming (Jang et al., 2014). Other research revealed that the proteasome could prevent transcription factors from binding to tissue-specific gene regions in ESCs, so that the differentiation-associated genes are restricted at the pluripotent cell stage (Szutorisz et al., 2006).

There is also growing evidence of the importance of the UPS in ASCs. Studies revealed that F box E3 ubiquitin ligase (FBXW7) plays a crucial role in the self-renewal and differentiation of HSCs and NSCs (Matsumoto et al., 2011; Matsuoka et al., 2008; Reavie et al., 2010; Saez et al., 2018; Thompson et al., 2008). Furthermore, a combination of RNAi screening and shotgun proteomic analysis characterizes the opposing effects between deubiquitinating enzyme PSMD14 and the E3 ligase FBXW7 in maintaining cellular pluripotency (Buckley et al., 2012). In satellite cells, deficiency of an essential proteasomal component Rpt3 can reduce the proteasome activity, impair cell proliferation, and eventually lead to cell-cycle arrest (Kitajima et al., 2018). Furthermore, proteasomes also prevent the binding of certain transcription factor and RNA polymerase Pol II to tissue-specific genes in ESCs, which could contribute to cell fate determination (Szutorisz et al., 2006). In addition, vimentin, a key regulator of cellular protein stability, can recruit proteasomes to aggresomes to remove aggregates in NSCs, and to facilitate the activation of quiescent NSCs (Maybury-Lewis and Webb, 2020; Morrow et al., 2020).

Taken together, the UPS is essential for maintaining stemness in both PSCs and ASCs, and dysfunction of the UPS may contribute to perturbed stem cell function and fate control. The main differences between UPS-related cellular reactions in stem cells and those in differentiated cells were summarized in Fig. 2. Furthermore, ER-associated degradation (ERAD) is yet another quality control mechanism that allows for the proteasomal degradation of misfolded proteins in the ER (Carvalho et al., 2006; Hampton et al., 1996). However, the function of ERAD in stem cells has not been well studied. Recently, a bioRxiv preprint revealed the essential role of ERAD in preserving the function of quiescent HSCs (Liu et al., 2019). Deficiency of an ERAD associated gene, Sel1L, reduced self-renewal and resulted in HSC depletion (Liu et al., 2019).

\section{Autophagy}

Misfolded and aggregated proteins can also be degraded by a separate autophagy-mediated pathway. Autophagy 
is a highly conserved intracellular process, in which damaged or unwanted proteins, cytosolic fractions, and organelles are degraded by the lysosome ( $\mathrm{He}$ and Klionsky, 2009). It is characterized by the engulfment of the targeted cytoplasmic components with a doublemembrane vesicle, forming the autophagosome. The autophagosome then fuses with the lysosome, where the encapsulated contents are released and degraded by lysosomal enzymes. In this process, the released nutrients, i.e. peptides, free amino acids, and fatty acids, can be recycled for ATP generation or protein synthesis (Mizushima, 2007). Intrinsic and extrinsic stress conditions, such as ER stress, ROS, hypoxia, starvation, and bacterial infections, are well-characterized inducers of autophagy (Chen et al., 2009; Singh and Cuervo, 2011; Yorimitsu and Klionsky, 2007).

Despite extensive research on autophagy in somatic cell physiology, relatively little is known about the roles of autophagy in stem cell biology. Recent studies report that autophagy is crucial for ESCs and for various ASCs, i.e. HSCs, MSCs, NSCs, and gut stem cells, although with different requirements for its activity (He et al., 2020; Liu et al., 2017; Mizushima et al., 2001; Mortensen et al., 2011; Peng et al., 2017; Sanchez et al., 2011).

In contrast to the high levels of proteasome activity observed during self-renewal, high levels of autophagy activity was exhibited during early differentiation of ESCs and NSCs (Tra et al., 2011; Vazquez et al., 2012). For example, deficiency of Apg 5 in mESCs causes defects in autophagosome formation and consequent accumulation of proteins in the cytoplasm (Mizushima et al., 2001). Mutant mice lacking beclin-1, a mammalian ortholog of the yeast autophagy-related gene 6 , die early in embryogenesis, and the autophagic response in mESCs is significantly altered as a result of the beclin-1 deficiency (Yue et al., 2003). Additionally, immunogoldelectron microscopy directly confirmed the localization of OCT4 molecules within autophagosomes, and inhibiting autophagy increases the accumulation of pluripotency-associated proteins in hESCs (Cho et al., 2014). In dormant NSCs, lysosomal pathways are activated to clear protein aggregates, thus restoring them to the young state (Leeman et al., 2018). Inhibition of this pathway has been related to some neurodegenerative disorders, cancers, and aging (Chen et al., 2011; Levine and Kroemer, 2008; Rubinsztein et al., 2011). Furthermore, increasing the expression of several autophagy-related genes promotes the differentiation of NSCs into neurons (Vazquez et al., 2012). NSCs with heterozygous deficiency of Ambra1, an autophagy gene, are impaired for neuronal generation (Vazquez et al., 2012).

Different from ESC sand NSCs, in which autophagy activity is required during differentiation, autophagy activity is decreased during the differentiation of MSCs, HSCs, dermal stem cells, and epiblast stem cells (Mortensen et al., 2011; Nuschke et al., 2014; Oliver et al., 2012; Pan et al., 2013; Salemi et al., 2012). Although hMSCs exhibit high levels of intrinsic autophagy during self-renewal, upon differentiation into osteoblasts or neurons, autophagy is attenuated to a relatively low level (Oliver et al., 2012). Similarly, upon the induction of osteogenic and adipogenic differentiation, the autophagosome marker LC3 II is lost in the early stage of differentiation (Nuschke et al., 2014). On the other hand, slightly increasing autophagy activity can protect MSCs from hypoxia- or ischemia-induced injury (Hu et al., 2019). Similarly, microRNA (miR)-142-5p was found at a high level in MSCs derived from bone marrow of aged mice and can cause ROS accumulation through the disruption of selective autophagy for peroxisomes (pexophagy). Thus, endothelial PAS domain protein 1 (EPAS1) targeted by miR-142-5p has been identified as a regulatory protein of pexophagy (Houri et al., 2020). Under starvation conditions or rapamycin treatment, autophagy is activated to cope with DNA damage induced by oxidative stress and to maintain MSC pluripotency. When the activity of autophagy is inhibited, the stemness of MSC is lost (Hou et al., 2013). Moreover, impaired autophagy activity in HSCs caused by knocking out either autophagy gene Atg7 or Fip200 in the hematopoietic system results in the loss of normal HSC function and death of the mice, suggesting that both autophagy genes are necessary for adult HSC maintenance (Liu et al., 2010; Mortensen et al., 2011). Maintaining a high basal autophagy flux can attenuate proteotoxicity in quiescent satellite cells (García-Prat et al., 2016). While in dormant breast cancer stem cells, targeted removal of $\operatorname{Atg} 3$ or $\operatorname{Atg} 7$ can inactivate autophagy and restore the expression of 6-photofructo-2-kinase/frutose-2,6biphosphatase 3, which can in turn restart cell proliferation (Flynn et al., 2019). Blocking the expression of ATG5 or 3methyladenine (3-MA) with shRNAs, thereby inhibiting autophagy, impairs the self-renewal capacity in epidermal stem cells, dermal stem cells, and HSCs. Atg5 plays a key role in the maintenance of HSCs, and the reconstitution ability of Atg5-deficient HSCs in bone marrow of chimeric mice is significantly impaired (Jung et al., 2019). Inhibiting the sphingolipid enzyme DEGS1 can induce autophagy to maintain functional HSCs (Xie et al., 2019). Autophagy-related genes such as Atg5, Atg7, and Atg12 can mediate the self-renewal, differentiation, and regeneration of the muscle and hematopoietic system, and the overexpression of Atg7 can rejuvenate aged satellite cells and HSCs and restore their regeneration ability (García-Prat et al., 2016; Ho et al., 2017). Moreover, the transcription factor FOXO3 is involved in autophagy induction of NSPCs and functions through autophagy-dependent pathways in NSPC maintenance (Audesse et al., 2019). These 
findings strongly suggested that autophagy participates in maintaining the stemness and homeostasis of various adult stem cells.

Likewise, autophagy is essential for iPSC reprogramming. A distinguishing feature of iPSCs is that the existing number and mass of mitochondria in the somatic cell origins are strikingly diminished during reprogramming. Hence, their metabolic pattern is switched from oxidative phosphorylation to glycolysis and this is considered as an important mechanism in iPSC reprogramming. ATG3-dependent autophagy can act as an executor for mitochondrial clearance during somatic cell reprogramming (Liu et al., 2016a). Even though it is debatable whether or not the ATG5-dependent canonical autophagy is necessary for reprogramming, the two research groups agreed on that autophagy is indispensable for iPSC reprogramming (Ma et al., 2015; Wang et al., 2013). Furthermore, during the reprogramming process induced by the four Yamanaka factors, Oct4, Sox2, Klf4, and c-Myc, the expression level of mTORC1 is downregulated and autophagy-related genes are induced (Wang et al., 2013; Wu et al., 2015). However, there is also some debates about how these phenomena are triggered by the four reprogramming factors. Introducing these factors into reprogramming cells individually showed that only ectopic expression of Sox2 downregulates mTOR expression and facilitates the induction of autophagy (Wang et al., 2013). By contrast, another study suggested that the four factors repress mTORC1 collaboratively, while only Klf4 and c-Myc promote the induction of autophagy-related genes, and Sox 2 and Oct4 inhibit their expression (Wu et al., 2015). In summary, the role of autophagy is crucial for successful reprogramming, but the underpinning mechanisms need to be further studied.

\section{Conclusions and perspectives}

Previous studies have revealed that genomic and epigenetic stability is essential for stem cell identity. Yet recent years have seen increasing evidence that supported a pivotal role for proteostasis in regulating pluripotency and differentiation of stem cells as well. Under physiological conditions, the proteostasis network is equipped with high versatility in response to distinct stimuli (Balch et al., 2008; Labbadia and Morimoto, 2015; Powers et al., 2009). During the differentiation of hESCs, both proteasome and autophagy are activated to prevent the delivery of damaged proteins to their self-renewed and differentiated counterparts. Unlike somatic cells, stem cells exhibit a highly regulated network for protein homeostasis as related to their biological characteristics (Lee et al., 2017). Even though transcriptional factors and epigenetic regulators have been recognized as the determinant of stem cell properties, there are also mounting evidence suggesting that an elaborate proteostasis network is crucial for stemness (Aguilo et al., 2015; Heintzman et al., 2009; Lee et al., 2017; San Jose et al., 2020; Yan et al., 2020; You et al., 2015). For example, defects in tRNA editing increase the accumulation of misfolded protein, which overwhelms the proteasomes in HSCs, and eventually impair its proliferation (San Jose et al., 2020). Likewise, chaperones also serve as significant determinants for stem cell pluripotency and differentiation (Bradley et al., 2012). In mESCs, the absence of Hsp60 and Hsp90 inhibits the expression of Oct4 by participating in the processing of Oct4 mRNA (Bradley et al., 2012; Seo et al., 2018). Therefore, deciphering the proteostasis network and their interaction with the regulators of epigenome and transcriptome for maintaining the function of stem cells is worthy of further research.

Furthermore, defects in proteostasis lead to the dysfunction of somatic stem cells, and eventually result in impairment of organismal development and aging, which encourages studies of PQC in search of treatment of aging and aging-related diseases. Pathological conditions, environmental and metabolic stresses, and aging contribute to the production of aberrant proteins in addition to the normal and physiological sources of misfolded proteins (Haigis and Yankner, 2010). To maintain cellular protein homeostasis and restore viability, cells have developed a precise network to regulate and preserve the integrity of the proteome. Chaperones are essential for assisting protein folding and refolding of nascent and aberrant proteins. If the aberrant proteins cannot be refolded, they will be degraded through the ubiquitin-proteasome system or autophagy. Hence, deciphering in more detail the role of proteostasis during these events and the mechanisms underlying these changes will shed new light on the relationship between PQC and stem cell biology. As reviewed here, increasing evidence demonstrates that proteostasis plays a key role in the regulation of pluripotency (Lee et al., 2017). In addition, the regulators of PQC can also be core components in assisting the reprogramming process (Buckley et al., 2012).

Study of the regulatory network in proteostasis will also provide new aspects in understanding embryonic development, aging, and pathogenesis. For instance, misfolded proteins have been linked to many neurodegenerative diseases such as Huntington's disease, Parkinson's disease, and Alzheimer's disease, in which aberrant protein aggregates overwhelm the cellular clearance machinery (Bosco et al., 2011; Finkbeiner, 2011; Schmidt and Finley, 2014; Selkoe, 2011). Recent researches suggested that protein misfolding is a key contributor to the progression of several diseases (Crunkhorn, 2015; Hartl et al., 2011) and loss of proteostasis has been implicated in stem cell aging (García-Prat et al., 2016). Failure of autophagy in physiologically aged satellite cells or 
genetic impairment of autophagy in young satellite cells results in senescence due to loss of proteostasis, accompanied by mitochondrial dysfunction and oxidative stress (García-Prat et al., 2016; Kapetanou et al., 2017). Further support for the link between PQC and longevity comes from studies demonstrating the activation of protein clearance mechanisms in longevity promoting pathways, which contribute to the amelioration of age-related diseases (Chondrogianni et al., 2000; Kapeta et al., 2010; Kenyon, 2010; Pérez et al., 2009). Further studies in mammals, especially in non-human primates, are required to unravel the potential links among PQC, aging, neurodegenerative disorders, and cancer. Nonetheless, increasing evidence supports the assertion that modulating PQC systems in stem cells will facilitate cell differentiation and reprogramming, interfere with cellular senescence, and sequentially reveal treatments with potential applications in clinical cell therapy. With this in mind, it will be crucial to develop drugs that activate the PQC systems to maintain proteostasis, potentially providing valuable therapeutic approaches for the treatment of aging and aging-related diseases.

\begin{abstract}
Abbreviations
PQC: Protein quality control; ESCs: Embryonic stem cells; ASCs: Adult stem cells; iPSCs: Induced pluripotent stem cells; PSCs: Pluripotent stem cells; ER: Endoplasmic reticulum; UPR: Unfolded protein response; UPS: Ubiquitinproteasome system; HSPs: Heat shock proteins; NSCs: Neural stem cells; MSCs: Mesenchymal stem cells; NSPCs: Neural stem and progenitor cells; $U_{U P R}{ }^{E R}$ : ER unfolded protein response; ATF6: Activated transcription factor 6; PERK: Double stranded RNA activated protein kinase-like ER kinase; IRE1a: inositol-requiring transmembrane kinase and endonuclease; HSCs: Hematopoietic stem cells; ROS: Reactive oxygen species; PAK2: p21activated kinase 2; XBP1: X-box binding protein 1; UPR ${ }^{\mathrm{MT}}$ : Mitochondrial unfolded protein response; Nrf2: Nuclear factor erythroid 2-like 2; FBXW7: F box E3 ligase; ERAD: ER-associated degradation; EPAS1: Endothelial PAS domain protein 1; Pexophagy: Autophagy for peroxisomes
\end{abstract}

\section{Acknowledgements}

The authors acknowledge J. Ping, J. Zhou, J. Li, X. He, and Y. Yang for stimulating discussions and critical reading. The authors thank $\mathrm{Q}$. Wang for polishing figures. The authors are also grateful to L. Bai, R. Bai, Q. Chu, J. Lu, Y. Yang, X. Zhuo, and S. Ma for administrative assistance.

\section{Authors' contributions}

P.Y., J.R., W.Z., J.Q., and G.-H.L. conceived and wrote the paper. All authors read and checked the final manuscript.

\section{Funding}

This work was supported by the Strategic Priority Research Program of the Chinese Academy of Sciences (XDA16010100), the National Key Research and Development Program of China (2018YFC2000100), the National Natural Science Foundation of China (81625009, 81921006, 81822018).

\section{Competing interests}

The authors declare that they have no competing interests.

\section{Author details}

${ }^{1}$ State Key Laboratory of Membrane Biology, Institute of Zoology, Chinese Academy of Sciences, Beijing 100101, China. ${ }^{2}$ University of Chinese Academy of Sciences, Beijing 100049, China. ${ }^{3}$ China National Center for Bioinformation, Beijing 100101, China. ${ }^{4}$ CAS Key Laboratory of Genomic and Precision Medicine, Collaborative Innovation Center of Genetics and Development, Beijing Institute of Genomics, Chinese Academy of Sciences, Beijing 100101,
China. ${ }^{5}$ Institute for Stem cell and Regeneration, Chinese Academy of Sciences, Beijing 100101, China. 'State Key Laboratory of Stem Cell and Reproductive Biology, Institute of Zoology, Chinese Academy of Sciences, Beijing 100101, China. ${ }^{7}$ Beijing Institute for Brain Disorders, Advanced Innovation Center for Human Brain Protection, National Clinical Research Center for Geriatric Disorders, Xuanwu Hospital Capital Medical University, Beijing 100053, China.

Received: 17 July 2020 Accepted: 14 September 2020

Published online: 12 November 2020

\section{References}

Aguilo F, Zhang F, Sancho A, Fidalgo M, Di Cecilia S, Vashisht A, Lee D-F, Chen C$H$, Rengasamy M, Andino B. Coordination of m6A mRNA methylation and gene transcription by ZFP217 regulates pluripotency and reprogramming. Cell Stem Cell. 2015;17:689-704.

Araki K, Nagata K. Protein folding and quality control in the ER. Cold Spring Harb Perspect Biol. 2011;3:a007526.

Asherie N. Protein crystallization and phase diagrams. Methods. 2004;34:266-72.

Assou S, Cerecedo D, Tondeur S, Pantesco V, Hovatta O, Klein B, Hamamah S, De Vos J. A gene expression signature shared by human mature oocytes and embryonic stem cells. BMC Genomics. 2009;10:10..

Atlasi Y, Stunnenberg HG. The interplay of epigenetic marks during stem cell differentiation and development. Nat Rev Genet. 2017;18:643-58..

Audesse AJ, Dhakal S, Hassell LA, Gardell Z, Nemtsova Y, Webb AE. FOXO3 directly regulates an autophagy network to functionally regulate proteostasis in adult neural stem cells. PLoS Genet. 2019;15:e1008097.

Avgustinova A, Benitah SA. Epigenetic control of adult stem cell function. Nat Rev Mol Cell Biol. 2016;17:643.

Avilion AA, Nicolis S, Pevny L, Perez L, Vivian N, Lovellbadge R. Multipotent cell lineages in early mouse development depend on SOX2 function. Genes Dev. 2003;17:126-40.

Baharvand H, Fathi A, Gourabi H, Mollamohammadi S, Salekdeh GH. Identification of mouse embryonic stem cell-associated proteins. J Proteome Res. 2008;7: $412-23$.

Baharvand H, Fathi A, Van Hoof D, Salekdeh GH. Concise review: trends in stem cell proteomics. Stem Cells. 2007;25:1888-903.

Baharvand H, Hajheidari M, Ashtiani SK, Salekdeh GH. Proteomic signature of human embryonic stem cells. Proteomics. 2006;6:3544-9.

Balch WE, Morimoto Rl, Dillin A, Kelly JW. Adapting proteostasis for disease intervention. Science. 2008;319:916-9.

Battersby A, Jones RD, Lilley KS, McFarlane RJ, Braig HR, Allen ND, Wakeman JA. Comparative proteomic analysis reveals differential expression of $\mathrm{Hsp} 25$ following the directed differentiation of mouse embryonic stem cells. Biochimica et Biophysica Acta (BBA)-Mol cell Res. 2007;1773:147-56.

Bennett EJ, Bence NF, Jayakumar R, Kopito RR. Global impairment of the ubiquitin-proteasome system by nuclear or cytoplasmic protein aggregates precedes inclusion body formation. Mol Cell. 2005;17:351-65.

Binder P, Wang S, Radu M, Zin M, Collins L, Khan S, Li Y, Sekeres K, Humphreys N, Swanton E. Pak2 as a novel therapeutic target for Cardioprotective endoplasmic reticulum stress response. Circ Res. 2019;124:696-711.

Bosco DA, LaVoie MJ, Petsko GA, Ringe D. Proteostasis and movement disorders: Parkinson's disease and amyotrophic lateral sclerosis. Cold Spring Harb Perspect Biol. 2011:3:a007500.

Boudesco C, Cause S, Jego G, Garrido C. Hsp70: A Cancer target inside and outside the cell. Methods in molecular biology (Clifton, NJ). 2018;1709: $371-96$.

Bradley E, Bieberich E, Mivechi NF, Tangpisuthipongsa D, Wang G. Regulation of embryonic stem cell pluripotency by heat shock protein 90. Stem Cells. 2012; 30:1624-33.

Brehme M, Voisine C, Rolland T, Wachi S, Soper JH, Zhu Y, Orton K, Villella A, Garza D, Vidal M, et al. A chaperome subnetwork safeguards proteostasis in aging and neurodegenerative disease. Cell Rep. 2014;9:1135-50.

Buckley SM, Aranda-Orgilles B, Strikoudis A, Apostolou E, Loizou E, Moran-Crusio K, Farnsworth CL, Koller AA, Dasgupta R, Silva JC, et al. Regulation of pluripotency and cellular reprogramming by the ubiquitin-proteasome system. Cell Stem Cell. 2012;11:783-98.

Carvalho P, Goder V, Rapoport TA. Distinct ubiquitin-ligase complexes define convergent pathways for the degradation of ER proteins. Cell. 2006;126: $361-73$. 
Chambers I, Colby D, Robertson M, Nichols J, Lee S, Tweedie S, Smith A. Functional expression cloning of Nanog, a pluripotency sustaining factor in embryonic stem cells. Cell. 2003;113:643-55.

Chen B, Retzlaff M, Roos T, Frydman J. Cellular strategies of protein quality control. Cold Spring Harb Perspect Biol. 2011;3:a004374.

Chen $Y$, Azad MB, Gibson SB. Superoxide is the major reactive oxygen species regulating autophagy. Cell Death Differentiation. 2009;16:1040-52.

Cho YH, Han KM, Kim D, Lee J, Lee SH, Choi KW, Kim J, Han YM. Autophagy regulates homeostasis of pluripotency-associated proteins in hESCs. Stem Cells. 2014;32:424-35.

Cho YM, Jang YS, Jang YM, Chung SM, Kim HS, Lee JH, Jeong SW, Kim IK, Kim JJ, Kim KS, et al. Induction of unfolded protein response during neuronal induction of rat bone marrow stromal cells and mouse embryonic stem cells. Exp Mol Med. 2009;41:440-52.

Chondrogianni N, Petropoulos I, Franceschi C, Friguet B, Gonos ES. Fibroblast cultures from healthy centenarians have an active proteasome. Exp Gerontol. 2000;35:721-8.

Croce CM, Calin GA. miRNAs, cancer, and stem cell division. Cell. 2005;122:6-7.

Crunkhorn S. Neurodegenerative disease: phosphatase inhibitor prevents proteinmisfolding diseases. Nat Rev Drug Discov. 2015;14:386.

Cui C-P, Zhang Y, Wang C, Yuan F, Li H, Yao Y, Chen Y, Li C, Wei W, Liu CH. Dynamic ubiquitylation of Sox 2 regulates proteostasis and governs neural progenitor cell differentiation. Nat Commun. 2018;9:1-15.

DeLany JP, Floyd ZE, Zvonic S, Smith A, Gravois A, Reiners E, Wu X, Kilroy G, Lefevre M, Gimble JM. Proteomic analysis of primary cultures of human adipose-derived stem cells: modulation by adipogenesis. Mol Cell Proteomics. 2005:4:731-40.

Evans MJ, Kaufman MH. Establishment in culture of pluripotential cells from mouse embryos. Nature. 1981;292:154-6.

Fan G, Kranias EG. Small heat shock protein 20 (HspB6) in cardiac hypertrophy and failure. J Mol Cell Cardiol. 2011;51:574-7.

Fan G-C. Role of heat shock proteins in stem cell behavior. In: Progress in molecular biology and translational science (Elsevier); 2012. p. 305-22.

Fernandes CFdL, Iglesia RP, Escobar MIM, Prado MB, Lopes MH. Chaperones and beyond as key players in Pluripotency maintenance. Frontiers in cell and developmental biology. 2019:7:150.

Fink AL. Chaperone-mediated protein folding. Physiol Rev. 1999;79:425-49.

Finka A, Goloubinoff P. Proteomic data from human cell cultures refine mechanisms of chaperone-mediated protein homeostasis. Cell Stress Chaperones. 2013;18:591-605.

Finkbeiner S. Huntington's disease. Cold Spring Harb Perspect Biol. 2011;3: a007476.

Finley D. Recognition and processing of ubiquitin-protein conjugates by the proteasome. Annu Rev Biochem. 2009:78:477-513.

Flynn ALB, Calhoun BC, Sharma A, Chang JC, Almasan A, Schiemann WP. Autophagy inhibition elicits emergence from metastatic dormancy by inducing and stabilizing Pfkfb3 expression. Nat Commun. 2019:10:1-15.

Foshay KM, Gallicano Gl. miR-17 family miRNAs are expressed during early mammalian development and regulate stem cell differentiation. Dev Biol. 2009;326:431-43.

García-Prat L, Martínez-Vicente M, Perdiguero E, Ortet L, Rodríguez-Ubreva J, Rebollo E, Ruiz-Bonilla V, Gutarra S, Ballestar E, Serrano AL, et al. Autophagy maintains stemness by preventing senescence. Nature. 2016:529:37-42.

García-Prat L, Sousa-Victor P, Muñoz-Cánoves P. Proteostatic and metabolic control of stemness. Cell Stem Cell. 2017;20:593-608.

Geng Y, Zhao Y, Schuster LC, Feng B, Lynn DA, Austin KM, Stoklosa JD, Morrison JD. A chemical biology study of human pluripotent stem cells unveils HSPA8 as a key regulator of Pluripotency. Stem Cell Reports. 2015;5:1143-54.

Gidalevitz T, Prahlad V, Morimoto RI. The stress of protein Misfolding: from single cells to multicellular organisms. Cold Spring Harb Perspect Biol. 2011;3.

Gingold $H$, Pilpel Y. Determinants of translation efficiency and accuracy. Mol Syst Biol. 2011;7:481.

Glickman MH, Ciechanover A. The ubiquitin-proteasome Proteolytic pathway: destruction for the sake of construction. Physiol Rev. 2002;82:373-428.

Goldberg AL. Protein degradation and protection against misfolded or damaged proteins. Nature. 2003:426:895-9.

Haigis MC, Yankner BA. The aging stress response. Mol Cell. 2010;40:333-44.

Hampton R, Gardner R, Rine J. Role of 265 proteasome and HRD genes in the degradation of 3-hydroxy-3-methylglutaryl-CoA reductase, an integral endoplasmic reticulum membrane protein. Mol Biol Cell. 1996;7: 2029-44.
Hartl FU, Bracher A, Hayer-Hartl M. Molecular chaperones in protein folding and proteostasis. Nature. 2011;475:324-32.

He C, Klionsky DJ. Regulation mechanisms and signaling pathways of autophagy. Annu Rev Genet. 2009:43:67-93.

He X, Memczak S, Qu J, Belmonte JCl, Liu G-H. Single-cell omics in ageing: a young and growing field. Nature Metabolism. 2020;2:293-302.

Heijmans J, de Jeude JFvL, Koo B-K, Rosekrans SL, Wielenga MC, van de Wetering M, Ferrante M, Lee AS, Onderwater JJ, Paton JC. ER stress causes rapid loss of intestinal epithelial stemness through activation of the unfolded protein response. Cell Rep. 2013;3:1128-39.

Heintzman ND, Hon GC, Hawkins RD, Kheradpour P, Stark A, Harp LF, Ye Z, Lee LK, Stuart RK, Ching CW. Histone modifications at human enhancers reflect global cell-type-specific gene expression. Nature. 2009:459:108.

Hernebring M, Fredriksson A, Liljevald M, Cvijovic M, Norrman K, Wiseman J, Semb H, Nystrom T. Removal of damaged proteins during ES cell fate specification requires the proteasome activator PA28. Sci Rep. 2013;3:1381.

Hetz C. The unfolded protein response: controlling cell fate decisions under ER stress and beyond. Nat Rev Mol Cell Biol. 2012;13:89-102.

Hetz C, Zhang K, Kaufman RJ. Mechanisms, regulation and functions of the unfolded protein response. Nat Rev Mol Cell Biol. 2020;21:421-38.

Ho TT, Warr MR, Adelman ER, Lansinger OM, Flach J, Verovskaya EV, Figueroa ME, Passegué E. Autophagy maintains the metabolism and function of young and old stem cells. Nature. 2017:543:205-10.

Hou J, Han ZP, Jing YY, Yang X, Zhang SS, Sun K, Hao C, Meng Y, Yu FH, Liu XQ, et al. Autophagy prevents irradiation injury and maintains stemness through decreasing ROS generation in mesenchymal stem cells. Cell Death Dis. 2013;4:e844.

Houri K, Mori T, Onodera Y, Tsujimoto T, Takehara T, Nakao S, Teramura T, Fukuda K. miR-142 induces accumulation of reactive oxygen species (ROS) by inhibiting pexophagy in aged bone marrow mesenchymal stem cells. Sci Rep. 2020;10:1-13.

Hsieh J, Gage FH. Epigenetic control of neural stem cell fate. Curr Opin Genet Dev. 2004:14:461-9.

Hu C, Zhao L, Wu D, Li L. Modulating autophagy in mesenchymal stem cells effectively protects against hypoxia- or ischemia-induced injury. Stem Cell Res Ther. 2019;10:120

Huang S, Xing Y, Liu Y. Emerging roles for the ER stress sensor IRE1a in metabolic regulation and disease. J Biol Chem. 2019;294:18726-41.

Jang J, Wang Y, Kim HS, Lalli MA, Kosik KS. Nrf2, a regulator of the proteasome, controls self-renewal and pluripotency in human embryonic stem cells. Stem Cells. 2014;32:2616-25.

Jarosz DF, Taipale M, Lindquist S. Protein homeostasis and the phenotypic manifestation of genetic diversity: principles and mechanisms. Annu Rev Genet. 2010;44:189-216.

Jee $\mathrm{H}$. Size dependent classification of heat shock proteins: a mini-review. Journal of exercise rehabilitation. 2016:12:255-9.

Jing R, Duncan CB, Duncan SA. A small-molecule screen reveals that HSP90ß promotes the conversion of induced pluripotent stem cell-derived endoderm to a hepatic fate and regulates HNF4A turnover. Development. 2017;144:1764-74.

Jung HE, Shim YR, Oh JE, Oh DS, Lee HK. The autophagy protein Atg5 plays a crucial role in the maintenance and reconstitution ability of hematopoietic stem cells. Immune Netw. 2019;19:e12

Kapeta S, Chondrogianni N, Gonos ES. Nuclear erythroid factor 2-mediated proteasome activation delays senescence in human fibroblasts. J Biol Chem. 2010;285:8171-84.

Kapetanou M, Chondrogianni N, Petrakis S, Koliakos G, Gonos ES. Proteasome activation enhances stemness and lifespan of human mesenchymal stem cells. Free Radic Biol Med. 2017;103:226-35.

Kappe G, Franck E, Verschuure P, Boelens WC, Leunissen JAM, Ww DJ. The human genome encodes 10 alpha-crystallin-related small heat shock proteins: HspB1-10. Cell Stress Chaperones. 2003;8:53-61.

Kenyon CJ. The genetics of ageing. Nature. 2010:464:504-12.

Kitajima Y, Suzuki N, Nunomiya A, Osana S, Yoshioka K, Tashiro Y, Takahashi R, Ono Y, Aoki M, Nagatomi R. The ubiquitin-proteasome system is indispensable for the maintenance of muscle stem cells. Stem cell reports. 2018;11:1523-38.

Kode JA, Mukherjee S, Joglekar MV, Hardikar AA. Mesenchymal stem cells: immunobiology and role in immunomodulation and tissue regeneration. Cytotherapy. 2009;11:377-91.

Koyuncu S, Saez I, Lee HJ, Gutierrez-Garcia R, Pokrzywa W, Fatima A, Hoppe T, Vilchez D. The ubiquitin ligase UBR5 suppresses proteostasis collapse in pluripotent stem cells from Huntington's disease patients. Nat Commun. 2018;9:2886. 
Labbadia J, Morimoto RI. The biology of proteostasis in aging and disease. Annu Rev Biochem. 2015;84:435-64.

Lee HJ, Gutierrez-Garcia R, Vilchez D. Embryonic stem cells: a novel paradigm to study proteostasis? FEBS J. 2017;284:391-8

Leeman DS, Hebestreit K, Ruetz T, Webb AE, McKay A, Pollina EA, Dulken BW, Zhao X, Yeo RW, Ho TT, et al. Lysosome activation clears aggregates and enhances quiescent neural stem cell activation during aging. Science. 2018; 359:1277-83.

Levine B, Kroemer G. Autophagy in the pathogenesis of disease. Cell. 2008;132: $27-42$.

Liu F, Lee JY, Wei H, Tanabe O, Engel JD, Morrison SJ, Guan JL. FIP200 is required for the cell-autonomous maintenance of fetal hematopoietic stem cells. Blood. 2010;116:4806-14.

Liu K, Zhao Q, Liu P, Cao J, Gong J, Wang C, Wang W, Li X, Sun H, Zhang C, et al. ATG3-dependent autophagy mediates mitochondrial homeostasis in pluripotency acquirement and maintenance. Autophagy. 2016a;12:2000-8.

Liu L, Inoki A, Fan K, Mao F, Shi G, Jin X, Zhao M, Ney G, Sun S, Dou Y, et al, Endoplasmic reticulum associated degradation preserves hematopoietic stem cell quiescence and self-renewal by restricting MTOR activity bioRxiv: 2019. p. 709964.

Liu P, Liu K, Gu H, Wang W, Gong J, Zhu Y, Zhao Q, Cao J, Han C, Gao F. High autophagic flux guards ESC identity through coordinating autophagy machinery gene program by FOXO1. Cell Death Differentiation. 2017;24: $1672-80$

Liu X, Yao Y, Ding H, Han C, Chen Y, Zhang Y, Wang C, Zhang X, Zhang Y, Zhai Y, et al. USP21 deubiquitylates Nanog to regulate protein stability and stem cell pluripotency. Signal transduction and targeted therapy. 2016b;1:16024.

Luo S, Mao C, Lee B, Lee AS. GRP78/BiP is required for cell proliferation and protecting the inner cell mass from apoptosis during early mouse embryonic development. Mol Cell Biol. 2006;26:5688-97.

Ma T, Li J, Xu Y, Yu C, Xu T, Wang H, Liu K, Cao N, Nie BM, Zhu SY, et al. Atg5independent autophagy regulates mitochondrial clearance and is essential for iPSC reprogramming. Nat Cell Biol. 2015;17:1379-87.

Martínez G, Khatiwada S, Costa-Mattioli M, Hetz C. ER proteostasis control of neuronal physiology and synaptic function. Trends Neurosci. 2018:41:610-24.

Martinez NJ, Gregory RI. MicroRNA gene regulatory pathways in the establishment and maintenance of ESC identity. Cell Stem Cell. 2010;7:31-5.

Matsumoto A, Onoyama I, Sunabori T, Kageyama R, Okano H, Nakayama Kl. Fbxw7dependent degradation of notch is required for control of "stemness" and neuronal-glial differentiation in neural stem cells. J Biol Chem. 2011;286:13754-64.

Matsuoka S, Oike Y, Onoyama I, Iwama A, Arai F, Takubo K, Mashimo Y, Oguro H, Nitta E, Ito K. Fbxw7 acts as a critical fail-safe against premature loss of hematopoietic stem cells and development of T-ALL. Genes Dev. 2008;22:986-91.

Maybury-Lewis SY, Webb AE. Taking prisoners: Vimentin cages capture proteasomes during NSC activation. Cell Stem Cell. 2020;26:473-5.

Mcclellan AJ, Tam S, Kaganovich D, Frydman J. Protein quality control: chaperones culling corrupt conformations. Nat Cell Biol. 2005;7:736-41.

Meissner A. Epigenetic modifications in pluripotent and differentiated cells. Nat Biotechnol. 2010;28:1079-88

Michels AA, Kanon B, Konings AW, Ohtsuka K, Bensaude O, Kampinga HH. Hsp70 and $\mathrm{Hsp} 40$ chaperone activities in the cytoplasm and the nucleus of mammalian cells. J Biol Chem. 1997;272:33283-9.

Mizushima N. Autophagy: process and function. Genes Dev. 2007;21:2861-73.

Mizushima N, Yamamoto A, Hatano M, Kobayashi Y, Kabeya Y, Suzuki K, Tokuhisa T, Ohsumi Y, Yoshimori T. Dissection of Autophagosome formation using Apg5-deficient mouse embryonic stem cells. J Cell Biol. 2001;152:657-68.

Mohrin M, Shin J, Liu Y, Brown K, Luo H, Xi Y, Haynes CM, Chen D. A mitochondrial UPR-mediated metabolic checkpoint regulates hematopoietic stem cell aging. Science. 2015;347:1374-7.

Mohrin M, Widjaja A, Liu Y, Luo H, Chen D. The mitochondrial unfolded protein response is activated upon hematopoietic stem cell exit from quiescence. Aging Cell. 2018;17:e12756.

Morrow CS, Porter TJ, Xu N, Arndt ZP, Ako-Asare K, Heo HJ, Thompson EA, Moore DL. Vimentin coordinates protein turnover at the Aggresome during neural stem cell quiescence exit. Cell Stem Cell. 2020;26:558-68.

Mortensen M, Soilleux EJ, Djordjevic G, Tripp R, Lutteropp M, Sadighi-Akha E, Stranks AJ, Glanville J, Knight S, Jacobsen SE, et al. The autophagy protein Atg7 is essential for hematopoietic stem cell maintenance. J Exp Med. 2011; 208:455-67.

Mukhopadhyay D, Riezman H. Proteasome-independent functions of ubiquitin in endocytosis and signaling. Science. 2007;315:201-5.
Nguyen DTT, Richter D, Michel G, Mitschka S, Kolanus W, Cuevas E, Wulczyn FG. The ubiquitin ligase LIN41/TRIM71 targets p53 to antagonize cell death and differentiation pathways during stem cell differentiation. Cell Death Differentiation. 2017;24:1063-78.

Nichols J, Zevnik B, Anastassiadis K, Niwa H, Klewenebenius D, Chambers I, Scholer HR, Smith A. Formation of pluripotent stem cells in the mammalian embryo depends on the POU transcription factor Oct4. Cell. 1998;95:379-91.

Noormohammadi A, Calculli G, Gutierrez-Garcia R, Khodakarami A, Koyuncu S, Vilchez D. Mechanisms of protein homeostasis (proteostasis) maintain stem cell identity in mammalian pluripotent stem cells. Cell Mol Life Sci. 2018;75:275-90.

Noormohammadi A, Khodakarami A, Gutierrez-Garcia R, Lee HJ, Koyuncu S, König T, Schindler C, Saez I, Fatima A, Dieterich C. Somatic increase of CCT8 mimics proteostasis of human pluripotent stem cells and extends C. elegans lifespan. Nat Commun. 2016;7:1-15.

Nuschke A, Rodrigues M, Stolz DB, Chu CT, Griffith LG, Wells A. Human mesenchymal stem cells/multipotent stromal cells consume accumulated autophagosomes early in differentiation. Stem Cell Res Ther. 2014:5:140.

Oliver L, Hue E, Priault M, Vallette FM. Basal autophagy decreased during the differentiation of human adult mesenchymal stem cells. Stem Cells Dev. 2012;21:2779-88.

Pan H, Cai N, Li M, Liu GH, Izpisua Belmonte JC. Autophagic control of cell 'stemness'. EMBO Mol Med. 2013;5:327-31.

Passier R, Mummery C. Origin and use of embryonic and adult stem cells in differentiation and tissue repair. Cardiovasc Res. 2003;58:324-35.

Peng Q, Qin J, Zhang Y, Cheng X, Wang X, Lu W, Xie X, Zhang S. Autophagy maintains the stemness of ovarian cancer stem cells by FOXA2. J Exp Clin Cancer Res. 2017;36:171.

Pérez VI, Buffenstein R, Masamsetti V, Leonard S, Salmon AB, Mele J, Andziak B, Yang $T$, Edrey $Y$, Friguet B. Protein stability and resistance to oxidative stress are determinants of longevity in the longest-living rodent, the naked molerat. Proc Natl Acad Sci. 2009;106:3059-64.

Pessina A, Gribaldo L. The key role of adult stem cells: therapeutic perspectives. Curr Med Res Opin. 2006;22:2287-300.

Powers ET, Morimoto Rl, Dillin A, Kelly JW, Balch WE. Biological and chemical approaches to diseases of proteostasis deficiency. Annu Rev Biochem. 2009; 78:959-91.

Reavie L, Gatta GD, Crusio K, Arandaorgilles B, Buckley SM, Thompson B, Lee E, Gao J, Bredemeyer AL, Helmink BA. Regulation of hematopoietic stem cell differentiation by a single ubiquitin ligase-substrate complex. Nat Immunol. 2010;11:207-15.

Revuelta M, Matheu A. Autophagy in stem cell aging. Aging Cell. 2017;16:912-5.

Richter K, Haslbeck M, Buchner J. The heat shock response: life on the verge of death. Mol Cell. 2010;40:253-66

Rouault-Pierre K, Lopez-Onieva L, Foster K, Anjos-Afonso F, Lamrissi-Garcia I, Serrano-Sanchez M, Mitter R, Ivanovic Z, de Verneuil H, Gribben J, et al. HIF2alpha protects human hematopoietic stem/progenitors and acute myeloid leukemic cells from apoptosis induced by endoplasmic reticulum stress. Cell Stem Cell. 2013;13:549-63.

Rubinsztein DC, Marino G, Kroemer G. Autophagy and aging. Cell. 2011;146:682-95.

Saez I, Koyuncu S, Gutierrez-Garcia R, Dieterich C, Vilchez D. Insights into the ubiquitin-proteasome system of human embryonic stem cells. Sci Rep. 2018; 8:1-21.

Salemi S, Yousefi S, Constantinescu MA, Fey MF, Simon HU. Autophagy is required for self-renewal and differentiation of adult human stem cells. Cell Res. 2012;22:432-5.

San Jose LH, Sunshine MJ, Dillingham CH, Chua BA, Kruta M, Hong Y, Hatters DM Signer RA. Modest declines in proteome quality impair hematopoietic stem cell self-renewal. Cell Rep. 2020;30:69-80 e66.

Sanchez CG, Penfornis P, Oskowitz A, Boonjindasup A, Cai DZ, Dhule SS, Rowan BG, Kelekar A, Krause DS, Pochampally R. Activation of autophagy in mesenchymal stem cells provides tumor stromal support. Carcinogenesis. 2011:32:964-72.

Saretzki G, Armstrong L, Leake A, Lako M, von Zglinicki T. Stress defense in murine embryonic stem cells is superior to that of various differentiated murine cells. Stem Cells. 2004;22:962-71.

Saretzki G, Walter T, Atkinson SP, Passos JF, Bareth B, Keith WN, Stewart R, Hoare SF, Stojkovic M, Armstrong L. Downregulation of multiple stress defense mechanisms during differentiation of human embryonic stem cells. Stem Cells. 2008;26:455-64.

Schmidt M, Finley D. Regulation of proteasome activity in health and disease Biochimica et Biophysica Acta (BBA)-molecular. Cell Res. 2014;1843:13-25. 
Schroder M, Kaufman RJ. ER stress and the unfolded protein response. Mutat Res. 2005;569:29-63.

Schroter F, Adjaye J. The proteasome complex and the maintenance of pluripotency: sustain the fate by mopping up? Stem Cell Res Ther. 2014;5:24.

Sciandra JJ, Subjeck JR. The effects of glucose on protein synthesis and thermosensitivity in Chinese hamster ovary cells. J Biol Chem. 1983:258:12091-3.

Seifert U, Kruger E. Remodelling of the ubiquitin-proteasome system in response to interferons. Biochem Soc Trans. 2008;36:879-84.

Selkoe D. Alzheimer's disease. Cold Spring Harb Perspect Biol. 2011;3:1-16.

Seo $\mathrm{N}-\mathrm{H}$, Lee $\mathrm{E}-\mathrm{H}$, Seo J-H, Song H-R, Han M-K. HSP60 is required for stemness and proper differentiation of mouse embryonic stem cells. Exp Mol Med. 2018;50:e459.

Shen G, Liu W, Xu L, Wang, L.-I. Mitochondrial unfolded protein response and its roles in stem cells. Stem Cells Dev. 2020;29:627-37.

Shenoy A, Blelloch RH. Regulation of microRNA function in somatic stem cell proliferation and differentiation. Nat Rev Mol Cell Biol. 2014;15:565-76.

Shu J, Wu C, Wu Y, Li Z, Shao S, Zhao W, Tang X, Yang H, Shen L, Zuo X. Induction of pluripotency in mouse somatic cells with lineage specifiers. Cell. 2013;153:963-75.

Sigurdsson V, Miharada K. Regulation of unfolded protein response in hematopoietic stem cells. Int J Hematol. 2018:107:627-33.

Simic MS, Moehle EA, Schinzel RT, Lorbeer FK, Halloran JJ, Heydari K, Sanchez M, Jullié $\mathrm{D}$, Hockemeyer D, Dillin A. Transient activation of the UPRER is an essential step in the acquisition of pluripotency during reprogramming. Sci Adv. 2019;5:eaaw0025.

Singh R, Cuervo AM. Autophagy in the cellular energetic balance. Cell Metab. 2011;13:495-504

Sterrenberg JN, Blatch GL, Edkins AL. Human DNAJ in cancer and stem cells. Cancer Lett. 2011;312:129-42.

Sugiura K, Muro Y, Futamura K, Matsumoto K, Hashimoto N, Nishizawa Y, Nagasaka T, Saito H, Tomita $Y$, Usukura J. The unfolded protein response is activated in differentiating epidermal keratinocytes. J Investig Dermatol. 2009; 129:2126-35.

Szutorisz H, Georgiou A, Tora L, Dillon N. The proteasome restricts permissive transcription at tissue-specific gene loci in embryonic stem cells. Cell. 2006 127:1375-88.

Taipale M, Jarosz DF, Lindquist S. HSP90 at the hub of protein homeostasis: emerging mechanistic insights. Nat Rev Mol Cell Biol. 2010;11:515-28.

Tanaka K, Matsuda N. Proteostasis and neurodegeneration: the roles of proteasomal degradation and autophagy. Biochim Biophys Acta. 2014;1843:197-204.

Thompson B, Jankovic V, Gao J, Buonamici S, Vest A, Lee JM, Zavadil J, Nimer SD, Aifantis I. Control of hematopoietic stem cell quiescence by the E3 ubiquitin ligase Fbw7. J Exp Med. 2008;205:1395-408.

Tra T, Gong L, Kao L, Li X, Grandela C, Devenish RJ, Wolvetang EJ, Prescott M. Autophagy in human embryonic stem cells. PLoS One. 2011;6:1-7.

Trepel JB, Mollapour M, Giaccone G, Neckers L. Targeting the dynamic HSP90 complex in cancer. Nat Rev Cancer. 2010;10:537-49.

Urra H, Dufey E, Avril T, Chevet E, Hetz C. Endoplasmic reticulum stress and the hallmarks of cancer. Trends Cancer. 2016;2:252-62.

van Galen P, Kreso A, Mbong N, Kent DG, Fitzmaurice T, Chambers JE, Xie S,

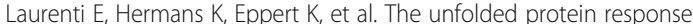
governs integrity of the haematopoietic stem-cell pool during stress. Nature. 2014;510:268-72.

Vazquez P, Arroba Al, Cecconi F, de la Rosa EJ, Boya P, de Pablo F. Atg5 and Ambra1 differentially modulate neurogenesis in neural stem cells. Autophagy. 2012;8:187-99.

Vilchez D, Boyer L, Lutz M, Merkwirth C, Morantte I, Tse C, Spencer B, Page L, Masliah E, Berggren WT. FOXO4 is necessary for neural differentiation of human embryonic stem cells. Aging Cell. 2013;12:518-22.

Vilchez D, Boyer L, Morantte I, Lutz M, Merkwirth C, Joyce D, Spencer B, Page L, Masliah E, Berggren WT. Increased proteasome activity in human embryonic stem cells is regulated by PSMD11. Nature. 2012;489:304-8.

Vilchez D, Saez I, Dillin A. The role of protein clearance mechanisms in organismal ageing and age-related diseases. Nat Commun. 2014a;5:5659.

Vilchez D, Simic MS, Dillin A. Proteostasis and aging of stem cells. Trends Cell Biol. 2014b:24:161-70.

Vonk WI, Rainbolt TK, Dolan PT, Webb AE, Brunet A, Frydman J. Differentiation drives widespread rewiring of the neural stem cell chaperone network. Mol Cell. 2020.

Voss AK, Thomas T, Gruss P. Mice lacking HSP90beta fail to develop a placental labyrinth. Development. 2000;127:1-11.
Wagers AJ, Weissman IL. Plasticity of adult stem cells. Cell. 2004;116:639-48.

Wang J-M, Qiu Y, Yang Z, Kim H, Qian Q, Sun Q, Zhang C, Yin L, Fang D, Back SH. IRE1a prevents hepatic steatosis by processing and promoting the degradation of select microRNAs. Sci Signal. 2018a;11:eaao4617.

Wang Q, Li X, Wang Q, Xie J, Xie C, Fu X. Heat shock pretreatment improves mesenchymal stem cell viability by heat shock proteins and autophagy to prevent cisplatin-induced granulosa cell apoptosis. Stem Cell Res Ther. 2019a;10:348.

Wang S, Hu B, Ding Z, Dang Y, Wu J, Li D, Liu X, Xiao B, Zhang W, Ren R. ATF6 safeguards organelle homeostasis and cellular aging in human mesenchymal stem cells. Cell Discovery. 2018b;4:1-19.

Wang S, Xia P, Ye B, Huang G, Liu J, Fan Z. Transient activation of autophagy via Sox2-mediated suppression of mTOR is an important early step in reprogramming to pluripotency. Cell Stem Cell. 2013;13:617-25.

Wang X, Karamariti E, Simpson R, Wang W, Xu Q. Dickkopf homolog 3 induces stem cell differentiation into smooth muscle lineage via ATF6 signalling. J Biol Chem. 2015;290:19844-52.

Wang Y, Medvid R, Melton C, Jaenisch R, Blelloch R. DGCR8 is essential for microRNA biogenesis and silencing of embryonic stem cell self-renewal. Nat Genet. 2007;39:380-5.

Wang Z, Kang L, Zhang H, Huang Y, Fang L, Li M, Brown PJ, Arrowsmith CH, Li J, Wong J. AKT drives SOX2 overexpression and cancer cell stemness in esophageal cancer by protecting SOX2 from UBR5-mediated degradation. Oncogene. 2019b;38:5250-64.

Wolff S, Weissman JS, Dillin A. Differential scales of protein quality control. Cell. 2014;157:52-64.

Wu H, Sun YE. Epigenetic regulation of stem cell differentiation. Pediatr Res. 2006; 59:21-5.

Wu Y, Li Y, Zhang H, Huang Y, Zhao P, Tang Y, Qiu X, Ying Y, Li W, Ni S, et al. Autophagy and $\mathrm{mTORC} 1$ regulate the stochastic phase of somatic cell reprogramming. Nat Cell Biol. 2015;17:715-25.

Xie, S.Z., Garcia-Prat, L., Voisin, V., Ferrari, R., Gan, O.l., Wagenblast, E., Kaufmann, K. B., Zeng, A.G., Takayanagi, S.-i., and Patel, I. (2019). Sphingolipid modulation activates Proteostasis programs to govern human hematopoietic stem cell self-renewal. Cell stem cell 25, 639-653. e637.

Xiong G, Hindi SM, Mann AK, Gallot YS, Bohnert KR, Cavener DR, Whittemore SR, Kumar A. The PERK arm of the unfolded protein response regulates satellite cell-mediated skeletal muscle regeneration. Elife. 2017;6:e22871.

Yamanaka S. A fresh look at iPS cells. Cell. 2009;137:13-7.

Yan P, Liu Z, Song M, Wu Z, Xu W, Li K, Ji Q, Wang S, Liu X, Yan K. Genome-wide R-loop landscapes during cell differentiation and reprogramming. Cell Rep. 2020:32:107870.

Yorimitsu T, Klionsky DJ. Eating the endoplasmic reticulum: quality control by autophagy. Trends Cell Biol. 2007;17:279-85.

You KT, Park J, Kim VN. Role of the small subunit processome in the maintenance of pluripotent stem cells. Genes Dev. 2015;29:2004-9.

Yu Z, Li Y, Fan H, Liu Z, Pestell RG. miRNAs regulate stem cell self-renewal and differentiation. Front Genet. 2012;3:191.

Yue Z, Jin S, Yang C, Levine AJ, Heintz N. Beclin 1, an autophagy gene essential for early embryonic development, is a haploinsufficient tumor suppressor. Proc Natl Acad Sci U S A. 2003:100:15077-82.

\section{Submit your manuscript to a SpringerOpen ${ }^{\circ}$ journal and benefit from:}

- Convenient online submission

- Rigorous peer review

- Open access: articles freely available online

- High visibility within the field

- Retaining the copyright to your article

Submit your next manuscript at $>$ springeropen.com 